\title{
Bioinformatic and Genomic Analyses of Cellular Reprogramming and Direct Lineage Conversion
}

\author{
Michael S. Kareta ${ }^{1,2,3,4}$ \\ Published online: 3 March 2016 \\ (C) Springer International Publishing AG 2016
}

Keywords Reprogramming · Bioinformatics · Genomics · Induced pluripotency $\cdot$ Direct lineage conversion

\section{Introduction}

Cellular reprogramming is a fantastically intriguing process where relatively simple changes are capable of forcing a cell to acquire a new and often completely separate identity. This remarkably simple technique, typically started by the forced overexpression of a few defined transcription factors, can be used to address many facets of modern biology. First observed in the forced conversion of related cell types, such as fibroblasts into myocytes or B lymphocytes into macrophages [21, 98], the potential for developmentally distant lineage cellular reprogramming was first realized with the discovery of induced pluripotency. The formation of induced pluripotent stem (iPS) cells revolutionized the perception of cell fate by showing that fully differentiated cells can be reprogrammed into a state nearly indistinguishable from embryonic stem (ES) cells [88]. Since then, reprogramming approaches have been utilized in direct lineage conversion of one cell type to another with no indication of passing through a pluripotent intermediate.

Reprogramming can shed light on many developmental processes. Observing cell fate acquisition illuminates the normal cellular processes associated with differentiation [83]. Additionally, the selection of reprogramming factors can better define their roles in developmental processes [36]. Reprogramming has the potential to also better delineate the processes that occur during aging as reprogramming has the ability to overcome some facets of the aging phenotype [57]. Additionally, reprogramming can be used to model aberrant cell fate changes, such as cancer [46, 48, 91]. Finally, reprogramming has brought the ideal of cell-based 
regenerative therapies within reach [86]. In particular, the hope for patient-specific cell therapies seems like a foregone conclusion now that that researchers and clinicians can in theory grow any cell from a patient, reprogram them to the cell of interest, repair any deficiencies ex vivo, and transplant the cells back into the patient.

However, there is still much to learn about reprogrammed cells, particularly in terms of understanding their reprogrammed state and how it reflects endogenous programs before they can be appropriately used to model developmental events or establish their suitability for therapeutic uses. Reprogramming, at its core, involves manifold changes to the entire gene expression networks. This is accompanied by global changes to the epigenome and other gene regulatory mechanisms. Monitoring these genomic-scale changes is further complicated by the rapid rate at which they occur. Indeed, these cell fates are reprogrammed in a matter of days in culture which might take significantly longer periods of time during normal development. Overshadowing these concerns is the difficulty that reprogramming itself is a very heterogeneous process. Together, these concerns require that monitoring cell fate changes involve observations on a genomic-scale, rather narrow time points to achieve appropriate resolution, and large enough observations to account for cellular heterogeneity which will be dependent on the reprogramming methodologies employed. It is therefore perhaps not surprising that computational approaches have played an essential role in the study of cellular reprogramming. Bioinformatics can be partially defined as the understanding of biological process using informatic methodologies such as computer science and statistics on a large, often genomic, scale [54]. Therefore, approaches such as whole-genome transcriptional analysis (microarrays and RNA-seq), the identification of genome-wide protein/DNA interactions (ChIP-chip and ChIP-seq), and other whole-genome analyses have been pivotal in the study of reprogramming. This review will address some of the bioinformatic and genomic approaches that have been applied to reprogramming (Table 1), initially focusing on induced pluripotent stem cells with a brief background on the bioinformatics of embryonic stem cells that serve as a critical benchmark to assess iPS cell identity, before addressing other forms of reprogramming including induced neurons (iNs), induced cardiomyocytes (iCMs), and induced hepatocytes (iHeps). Finally, future goals and improvements to the study of reprogramming processes will be discussed.

\section{Informatics in the Study of Pluripotency: Setting the Stage for Reprogramming}

Before cellular reprogramming became a common practice, a multitude of researchers were involved in using bioinformatic approaches to investigate the complex pluripotent state (reviewed in [22, 32, 67]). Microarray analysis was first utilized to perform transcriptional profiling of ES cells and to define the pluripotent network $[72,80]$. Once the core pluripotency transcription factors Oct4, Sox2, and Nanog were identified, genomic studies on their bound loci in ES cells could be performed. It was determined that these factors serve a twofold function in ES cells: to both upregulate a larger pluripotency and self-renewal network and to downregulate differentiation-specific genes [8]. It is notable that this was one of the first papers to analyze the regions of interaction of a protein with the DNA genome-wide, in part because of the ability to grow large amounts of ES cells without relying on transformed cell lines. With these two opposing gene networks identified, it was possible to investigate the means by which the core network can regulate their activities. Chromatin immunoprecipitation (ChIP) and transcriptional profiling determined that the polycomb repressive complex marks genes repressed by the core pluripotency network with H3K27me3, thereby silencing lineage-specific genes [9]. Indeed, many of these key lineage-specific genes are bivalently marked with both the repressive H3K27me3 and the activating $\mathrm{H} 3 \mathrm{~K} 4 \mathrm{me} 3$ histone modifications, resulting in a "poised" state whereby these genes can be rapidly expressed or repressed during differentiation [6]. This prompted a greater determination of other histone and DNA modifications in ES cells, including $\mathrm{H} 3 \mathrm{~K} 4 \mathrm{me} 3, \mathrm{H} 3 \mathrm{~K} 27 \mathrm{me} 3, \mathrm{H} 3 \mathrm{~K} 9 \mathrm{me} 3$, H3K20me3, H3K36me3, and 5meC [28, 51, 62]. These datasets also allowed for identification of microRNAs (miRs) that interact with the core pluripotency network to maintain pluripotency [59]. Finally, downstream networks as assayed by direct protein/protein interactions could then be identified that coordinately regulate the pluripotent state $[48$, 94]. The Encyclopedia of DNA Elements (ENCODE, http:// www.genome.gov/encode/) project is a multi-center consortium where many epigenetic modification and protein binding sites are mapped across the human genome, including human ES cells, and is a robust dataset for current and future bioinformatic studies of pluripotency [27].

\section{Bioinformatic Analysis of Induced Pluripotency}

Upon the discovery that mouse and human cells could be reprogrammed to a pluripotent state $[65,87,88,105]$, a great push was undertaken to shed light on this fascinating, albeit difficult to study, process (reviewed in [3, 69]). It was already clear through microarray analysis that these iPS cells had gene expression patterns similar to ES cells [87, 88, 105]. However, it was unclear if the differences observed between iPS and ES cell expression patterns were due to incomplete reprogramming or an inability to properly identify fully reprogrammed clones. Therefore, before reliable bioinformatic analysis could be performed, certain tools would be needed 
Table 1 Select datasets for bioinformatic analysis of reprogramming

\begin{tabular}{|c|c|c|c|c|c|}
\hline Data type & Reprogramming type & Description & Species & Data accession $^{\mathrm{a}}$ & Reference \\
\hline \multicolumn{6}{|c|}{ Gene expression } \\
\hline Microarray & iPS & Fibroblasts, iPS, ES & Mouse & GSE5259 & {$[88]$} \\
\hline Microarray & iPS & Fibroblasts, iPS, ES & Mouse & E-MEXP-1037 ${ }^{b}$ & [97] \\
\hline Microarray & iPS & $\begin{array}{l}\text { ES, Fbx } 15 \text {, and Nanog selected } \\
\text { iPS cells }\end{array}$ & Mouse & GSE7841 & {$[65]$} \\
\hline Microarray & iPS & Fibroblasts, iPS, ES & Mouse & GSE7815 & {$[56]$} \\
\hline Microarray & iPS & Fibroblasts, ES, iPS & Human & GSE9561 & {$[87]$} \\
\hline Microarray & iPS & Fibroblasts, ES, iPS & Human & GSE9164 & {$[105]$} \\
\hline Microarray & iPS & $\begin{array}{l}\text { Fibroblasts, B lymphocytes, ES, } \\
\text { iPS, partially reprogrammed iPS }\end{array}$ & Mouse & GSE10871 & [61] \\
\hline Microarray & iPS & Keratinocytes, human ES, and iPS & Human & GSE12390 & {$[55]$} \\
\hline Microarray & iPS & Fibroblasts, ES, and iPS & Human & GSE22499 & {$[31]$} \\
\hline Microarray & iPS & Fibroblasts and iPS & Human & GSE25970 & [7] \\
\hline Microarray & $\mathrm{iCM}$ & $\begin{array}{l}\text { Cardiac fibroblasts, iCMs, } \\
\text { neonatal cardiomyocytes }\end{array}$ & Mouse & GSE22292 & {$[41]$} \\
\hline Microarray & $\mathrm{iN}$ & $\begin{array}{l}\text { Fibroblasts, hepatocytes, } \\
\text { reprogramming intermediates, } \\
\text { iN, cortical neurons }\end{array}$ & Mouse & GSE30102 & {$[58]$} \\
\hline Microarray & iDA & $\begin{array}{l}\text { Fibroblasts, induced dopaminergic } \\
\text { (iDA) neurons, mesencephalic } \\
\text { dopaminergic neurons }\end{array}$ & Human & GSE27174 & {$[16]$} \\
\hline Microarray & iHEP & Fibroblasts, hepatocytes, iHEP & Mouse & GSE23635 & {$[37]$} \\
\hline Microarray & iHEP & Fibroblasts, hepatocytes, iHEP & Mouse & GSE29725 & {$[76]$} \\
\hline Microarray & ieSCs & Fibroblasts, primary sertoli cells, ieSCs & Mouse & GSE35653 & [13] \\
\hline RNA-seq & $\mathrm{iN}$ & $\begin{array}{l}\text { Fibroblasts, reprogramming } \\
\text { intermediates, iN }\end{array}$ & Mouse & GSE43916 & {$[95]$} \\
\hline Microarray & $\mathrm{iCM}$ & Fibroblasts, heart fibroblasts, iCM & Human & GSE43588 & {$[63]$} \\
\hline Microarray & $\mathrm{iCM}$ & $\begin{array}{l}\text { Dermal fibroblasts, ES-derived } \\
\text { fibroblasts, fetal cardiomyocytes, } \\
\text { iCM, ES-derived iCM }\end{array}$ & Human & GSE49192 & [29] \\
\hline Microarray & iHepSC & $\begin{array}{l}\text { Fibroblasts, iHeps, iHepSCs, } \\
\text { primary cholangiocytes, } \\
\text { iHepSC-derived cholangiocytes }\end{array}$ & Mouse & GSE48486 & [104] \\
\hline Microarray & iPS & Fibroblasts, OSKM-iPS, SNEL-iPS & Mouse & GSE45173 & {$[14]$} \\
\hline RNA-seq & iPS & $\begin{array}{l}\text { Fibroblasts, iPS, and } \\
\text { reprogramming intermediates }\end{array}$ & Mouse & SRP046744 & {$[40]$} \\
\hline Microarray & iHEP & Fibroblasts, primary hepatocytes, iHEP & Human & GSE42643 & {$[38]$} \\
\hline Microarray & $\mathrm{iECs}$ & Fibroblasts, primary ECs, iECs & Mouse & GSE50071 & {$[33]$} \\
\hline RNA-seq & iHEPs & Fibroblasts, primary hepatocytes, iHEPs & Human & GSE54066 & {$[24]$} \\
\hline Microarray & iHPCs & Fibroblasts, iHPCs & Mouse & GSE59428 & [4] \\
\hline Microarray & iMels & Fibroblasts, primary melanocytes, iMels & Human & GSE51028 & [101] \\
\hline Microarray & iPS & Reprogramming intermediates & Mouse & GSE6295 & [53] \\
\hline RNA-seq & iPS & Human-induced fibroblasts, iPS & Human & GSE62777 & {$[15]$} \\
\hline \multicolumn{6}{|c|}{ Genomic protein binding studies } \\
\hline ChIP-chip & iPS & H3K4me3, H3K27me3 & Mouse & GSE7815 & {$[56]$} \\
\hline ChIP-seq & iPS & H3K4me3, H3K27me3 & Mouse & GSE11074 & {$[61]$} \\
\hline ChIP-chip & iPS & $\begin{array}{l}\text { Oct4, Sox2, Klf4, c-Myc, Nanog, } \\
\text { Dax1, Rex1, Zpf281, and Nac1 }\end{array}$ & Mouse & GSE11329 & {$[47]$} \\
\hline ChIP-seq & iPS & H3K4me3, H3K27me3 & Human & GSE22499 & {$[31]$} \\
\hline ChIP-seq & iPS & H3K4me2, H3K27me3 & Mouse & GSE26100 & {$[50]$} \\
\hline ChIP-seq & $\mathrm{iN}$ & Ascl1, Brn2, Myt1L & Mouse & GSE43916 & {$[95]$} \\
\hline ChIP-seq & iPS & H3K4me3, H3K27me3, H3K36me3 & Mouse & SRP046744 & {$[40]$} \\
\hline ChIP-seq & iPS & Mediator, H2A.X & Mouse & $\begin{array}{l}\text { GSE59569, } \\
\text { GSE55731 }\end{array}$ & {$[14]$} \\
\hline
\end{tabular}


Table 1 (continued)

\begin{tabular}{|c|c|c|c|c|c|}
\hline Data type & Reprogramming type & Description & Species & Data accession $^{\mathrm{a}}$ & Reference \\
\hline ChIP-seq & iPS & $\begin{array}{l}\text { H3K4me2, H3K4me3, H3K27ac, } \\
\text { H3K36me3 }\end{array}$ & Human & GSE62777 & {$[15]$} \\
\hline \multicolumn{6}{|l|}{ DNA methylation } \\
\hline CHARM & iPS & Blood and fibroblast iPS & Mouse & GSE22851 & [49] \\
\hline RRBS & iPS & Early iPS intermediates & Mouse & GSE26100 & {$[50]$} \\
\hline MethylC-seq & iPS & $\begin{array}{l}\text { Fibroblasts, } \mathrm{iPS}, \text { and } \\
\quad \text { reprogramming intermediates }\end{array}$ & Mouse & ERP004116 ${ }^{\mathrm{d}}$ & [40] \\
\hline RRBS & iPS & Induced fibroblasts, iPS & Human & GSE62777 & {$[15]$} \\
\hline \multicolumn{6}{|c|}{ Whole-genome sequence } \\
\hline SNP Array & iPS & Fibroblasts and iPS & Human & GSE26173 & [39] \\
\hline WGS & iPS & Fibroblasts and iPS & Human & SRP005709 & {$[30]$} \\
\hline \multicolumn{6}{|l|}{ Others } \\
\hline 4C-seq & iPS & $\begin{array}{l}\text { Fibroblasts, partially } \\
\text { reprogrammed iPS and iPS }\end{array}$ & Mouse & GSE50029 & {$[23]$} \\
\hline FAIRE-seq & iN & Fibroblasts & Mouse & GSE43916 & {$[95]$} \\
\hline
\end{tabular}

${ }^{\text {a }}$ All accession numbers are from the NCBI Gene Expression Omnibus (GEO), unless noted

${ }^{\mathrm{b}}$ Available at the EMBL-EBI ArrayExpress

${ }^{c}$ Available at the NCBI Sequence Read Archive (SRA)

${ }^{\mathrm{d}}$ Available at the European Bioinformatics Institute, European Nucleotide Archive (ENA)

to standardize this extremely complex process. GFP reporter and antibiotic-selectable cell lines were first generated in murine cells to identify those clones that have achieved full pluripotency as indicated by activation of endogenous pluripotency genes $[56,60,97]$. This alone served to drastically improve the feasibility of bioinformatic analysis by defining cell lines for the large-scale purification of iPS cells as defined by core network activation. By the use of these iPS reporter lines, it was clear that the expression of iPS cells more closely matched that of an ES cell [56, 97].

These iPS reporters served to better define the endpoint of iPS reprogramming, yet there was still the issue that the starting cell population was typically mouse embryonic fibroblasts, which are themselves a heterogeneous and poorly defined starting point for any sort of integrative analysis [42]. To overcome this, other cell types were reprogrammed such as B lymphocytes $[35,61]$. While this represented a better starting point by reducing the heterogeneity of the starting cell type, the issue of variable transgene integration still confounded the starting cell population to hamper reliable analysis. This was solved by the generation of secondary iPS systems. These systems utilize cells isolated from iPS chimeric mice. The iPS cells which made the chimera were generated from doxycycline-inducible systems, and therefore, cells grown from these mice would have clonal integrations of the reprogramming factors which could then be reactivated by culture in doxycycline $[35,96]$. While previous studies had broken iPS reprogramming into intermediate steps [10, 84], this secondary system allowed for more reliable integrative bioinformatic analysis by better defining the starting point
(Dox induction) and reducing the variability of random proviral insertion. Expression profiles were generated which showed clear activation of ES gene sets in iPS clones, as well as identified genes which are upregulated in partially reprogrammed clones as well [61].

While not developing at the same pace as for the mouse, similar genetic tools for the study of human reprogramming have been emerging. Methodologies were first established to increase the efficiency of human reprogramming, which is less than that of the mouse [55, 87, 105]. Like in the mouse, initial studies showed that human iPS cells are very similar to ES cells [31], especially when grown in the presence of GSK3 $\beta$ and ERK inhibitors ( $2 \mathrm{i}$ conditions) which restore naïve pluripotency to human ES cells [34]. A recently generated secondary system for human reprogramming has been reported where differentiation of iPS colonies into fibroblasts created lines with clonal integrations of inducible reprogramming factors and constitutive hTERT to overcome senescence and the ability to expand clones. As with other systems, this secondary system generates human iPS cells that are generally very similar to ES cells in their gene expression profiles and histone modifications [15].

To assess the mechanisms behind reprogramming, the obvious starting point was an evaluation of the reprogramming factors themselves. These studies lent themselves to bioinformatic analysis due to the need to handle large datasets that address reprogramming factor binding sites and the consequence of binding on gene expression (reviewed in [75, 103]). There was already a push to evaluate Oct4 binding in ES cells which identified its downstream network and 
combined with expression data showed that Oct4 and Sox2 can both upregulate and downregulate targets [8, 52]. With the identification of Oct4, Sox2, Klf4, and $c-M y c$ as the canonical reprogramming factors, an effort was put forth to describe their function in relation to each other. It was observed that genes that were bound by multiple reprogramming factors are often upregulated while genes bound by just a few factors are typically repressed [47]. Additionally, genome binding and protein interaction network analysis showed that Myc operates on a separate network than Oct4, Sox2, and Klf4 to regulate proliferation in pluripotent cells $[48,81]$. Timed induction of the reprogramming factors combined with microarray analysis of expressional profiles at defined time points during reprogramming elucidated the global initiation events during reprogramming which included a mesenchymal-toepithelial transition [74]. Generally, there are two periods of reprogramming factor activity during iPS formation. The first is mediated by c-Myc and Klf4, and the second by Oct4, Sox2, and Klf4. This second wave of transcriptional activation is required for successful reprogramming [70]. Indeed, singlecell expression analysis identified Sox 2 to be critical in later stages of reprogramming where a defined network of gene activation establishes the iPS state [11]. Modifying the reprogramming factor cocktail can improve the functionality of the generated iPS cells. For example, it has been reported that Sall4, Nanog, Esrrb, and Lin28 better recapitulated an ES expressional network than Oct4, Sox2, Klf4, and c-Myc [14]. Genomic-scale analyses have also shown that both miRs and large noncoding RNAs may interact with the reprogramming factors to enhance reprogramming [25, 45, 59].

Bioinformatic analysis has been utilized to investigate iPS reprogramming not only at the level of gene expression and transcription factor binding but also at the epigenetic level. Globally, there is great similarity in the histone modifications $\mathrm{H} 3 \mathrm{~K} 4 \mathrm{me} 3$ and H3K27me3 between iPS and ES cells $[31,56]$. Observations at early reprogramming showed rapid increases of $\mathrm{H} 3 \mathrm{~K} 4 \mathrm{me} 2$ at pluripotency genes [50]. Investigation of reprogramming intermediates characterized by surface marker and Oct4 expression helped to define some of these changes throughout reprogramming. The authors found that bivalent domains are established early while DNA methylation changes are common in later stages [70]. Not surprisingly, many genes involved in the establishment of chromatin modification patterns regulate reprogramming [66]. Studying the epigenetics of iPS cells is not limited to changes during reprogramming, but also that of the starting cells themselves. While the reprogramming factors are mostly able to bind to chromatinized templates $[43,106]$, genomic regions in the starting cells that are heavily marked with $\mathrm{H} 3 \mathrm{~K} 9 \mathrm{me}$, a mark of heterochromatin, can indeed block the function of the Oct4, Sox2, and Klf4 and thereby inhibit reprogramming [79]. In contrast, broad domains of $\mathrm{H} 3 \mathrm{~K} 4 \mathrm{me} 3$ can enhance transcriptional consistency and are established at pluripotency genes during reprogramming [5]. As a consequence of these epigenetic modifications, there is a defined subnuclear organization to the genome in the cells during reprogramming that was identified by $4 \mathrm{C}$-seq and indicates a partitioning of pluripotency factor-bound loci and regions marked by H3K27me3 in iPS cells [23]. These types of integrative bioinformatic analyses have been useful in further characterizing other reprogramming states. An unbiased analysis of gene expression and epigenetic modifications of reprogrammed cells identified a state, termed F-class cells, which are pluripotent yet do not grow as typical ES cell colonies [90]. Expanded analysis of the reprogramming routes to the typical iPS state and the F-class state identifies that loss of promoter $\mathrm{H} 3 \mathrm{~K} 27 \mathrm{me} 3$ accompanies formation of a transient primed state. As cells then acquire pluripotency, promoter $\mathrm{H} 3 \mathrm{~K} 27 \mathrm{me} 3$ levels are reformed with a lack of DNA demethylation favoring the F-class state and active DNA demethylation with increased promoter $\mathrm{H} 3 \mathrm{~K} 4 \mathrm{me} 3$ required to form the ES-like state [40].

Generally, there is agreement that iPS reprogramming generates cells that are very similar to ES cells [15, 31, 55, 61, 74]; however, genomic-scale bioinformatics has been able to identify subtle differences between ES and iPS cells. An early meta-analysis of expressional profiling identified a subset of genes and miRs that can differentiate human iPS and ES cells [18]. While some of these differences may be due to laboratory-specific differences [31, 64], it appears that extended culture of iPS clones can abrogate some of these laboratory-specific differences [19]. The differences in gene expression can be explained in part by variable DNA methylation between iPS clones [7, 49]. Indeed, the variability of DNA methylation and gene expression between clones can influence the differentiation potential of iPS lines [7, 49]. Not only does reprogramming promote clone to clone variability but it can also introduce mutations as a consequence of reprogramming itself. Whole-genome sequencing of human iPS cell lines showed that there are point mutations introduced, often in genes that are themselves often mutated in cancer [30]. Some of these mutations can also be resolved with longer passaging, presumably to select against them and restore a more ES-like genetic state [39]. Using genetically matched human iPS and ES cells identified only 49 differentially expressed genes which did not affect the potential of these lines, leading the authors to conclude that genetic background has a greater influence on the differences between ES and iPS cells that has been previously observed, rather than a functional difference between these two cell types [20].

\section{Bioinformatic Analysis of Direct Lineage Reprogramming}

Once iPS reprogramming opened the possibility for other forms of reprogramming, it was not long until researchers sought to 
perform direct lineage conversion or transdifferentiation without a pluripotent intermediate. There is a debate in the literature over the terms direct lineage reprogramming or transdifferentiation, mostly stemming around the use of the term reprogramming to only refer to the formation of iPS cells $[44,77]$. For this review, a more general definition of reprogramming that describes cell fate changes imposed by defined media conditions or transcription factor overexpression [12] will be utilized to encompass iPS reprogramming and direct lineage reprogramming. While direct lineage reprogramming had been previously observed, for example, the conversion of fibroblasts to myoblasts [21], the advent of iPS reprogramming brought a greater emphasis on direct reprogramming that has since blossomed into a vibrant field of research. As the bioinformatic age was already well underway at this time, it was not surprising that bioinformatic analyses rapidly advanced the study of direct reprogramming. At the time of writing, there have been (approximately) 23 different generalized cell types formed by direct reprogramming (reviewed in [99]). A few of the prominent forms of post-iPS direct reprogramming will be discussed in light of how bioinformatic analysis has furthered their advancement and utility.

\section{Induced Neuronal Cells}

The first form of direct reprogramming was induced neuronal (iN) cells, where terminally differentiated mouse or human cells are reprogrammed into functional neurons $[1,68,92$, 102]. Since then, there have been a wide array of neural subtypes and neural-related cells formed by direct reprogramming (reviewed in $[2,89]$ ). In the first bioinformatic analysis of iN cell reprogramming, microarray analysis was utilized in an integrative manner throughout the reprogramming process and showed that iN cells (from either MEFs or hepatocytes) are indeed transcriptionally similar to cortical neurons with strong downregulation of donor-specific genes and upregulation of neural genes [58]. Similar results were shown using a modified reprogramming scheme to generate induced dopaminergic (iDA) neurons; however, these iDA cells could still be differentiated from mesencephalic dopaminergic neurons indicating a lack of complete lineage specification [16].

To better understand the mechanisms which underlie this reprogramming process, an extensive bioinformatic analysis was performed by Wapinski and colleagues who investigated the role of Ascll, one of the three canonical iN reprogramming factors along with Brn2 and Myt1L, and itself sufficient for iN cell formation $[17,95]$. They combined integrative RNA-seq analysis of iN cell reprogramming along with ChIP of the three reprogramming factors. They observed that Ascll acts as a pioneer factor by FAIRE-seq, a method to map the density of histone packaging genome-wide, and observed that Ascll then recruits Brn2 to neuronal targets during reprogramming.
Finally, by extensive meta-analysis of published histone modification ChIP data, they observed using a Hidden Markov Model that a "trivalent" chromatin mark consisting of H3K4me1, H3K27me3, and H3K9me3 favored Ascll binding [95].

\section{Induced Cardiomyocytes}

Not long after iN cells, the ability to directly reprogram cells to a cardiomyocyte lineage was reported ([26, 41]; reviewed in [82]). As required to show effective lineage conversion, the authors demonstrated that the global gene expression patterns in these induced cardiomyocytes (iCMs) were similar to primary cardiomyocytes, although some differences were observed [41]. Again, when human iCM reprogramming protocols were elucidated, expression analysis was critical in showing the global activation of cardiomyocyte-specific gene networks [29, 63, 93]. Fu and coworkers additionally showed using orthologous gene expression analysis that deficiencies in in vitro mouse iCM reprogramming can be overcome by reprogramming the cells in vivo, indicating that more complete human iCM reprogramming in vivo may be possible $[29,71,78]$.

\section{Induced Hepatocytes}

Hepatocytes are an important cell type for regenerative and drug screening purposes; therefore, there has been a concerted effort to elucidate mechanisms for the direct induction of nonliver cells into induced hepatocytes (iHEPs). The successfully generated iHEP cells from mouse by two separate groups were validated by expressional analysis $[37,76]$. Induced hepatic stem cells (iHepSCs), which possess the potential to differentiate into both hepatocytic and cholangiocytic cells, were characterized and their potential confirmed by global expression analysis [104]. Again, when a human iHEP reprogramming protocol was published, expressional analysis confirmed hepatocyte gene network activation [24, 38].

\section{Other Direct Reprogramming Methodologies}

Methods for the direct reprogramming of cells into a variety of defined cell types is only growing and is being further streamlined by the increasing abundance of tissue-specific and developmental gene expression datasets. With these datasets, investigators are able to generate candidate genes which may be capable of direct conversion as well as use defined lineage specific networks as a benchmark for proper lineage reprogramming. Many of these rely on a study of the gene expression networks in the target cells to confirm proper lineage conversion including hematopoietic stem and progenitor cells (iHSC, iHPC, [4, 73, 85]), embryonic sertoli-like cells (ieSCs, [13]), endothelial cells (iECs, [33]), and melanocytes (iMels, [101]). 


\section{Future Directions}

The application of bioinformatic analysis is indispensable to the study of cellular reprogramming. The global changes that occur in a cell to change its fate require a global investigation of gene network activation and chromatin states. Furthermore, to better understand the reprogramming process itself, an understanding of reprogramming factor function to both activate new gene networks and silence donor programs is needed to understand the mechanisms which underlie this seemingly mysterious process. To this end, further analysis of the mechanisms by which these handfuls of factors can reprogram a cell will be indispensable to understand reprogramming, as has been performed in both iPS and iN reprogramming [8, 11, $47,52,95]$. To achieve the precise timing and high efficiency that are so critical for these types of integrative analyses, secondary reprogramming systems, such as those that have been generated for iPS cells, have served as a profitable system for bioinformatic analysis $[15,35,40,50,61,74,90,96]$. While these secondary systems abrogate a great deal of the cellular heterogeneity found during reprogramming, they cannot overcome the cell-to-cell variability that is inherent to this system. Therefore, an analysis of reprogramming on the single-cell level will drastically illuminate the stepwise processes that occur in lineage conversion [11, 53, 107]. The improving feasibility of reliable single-cell expressional profiling also opens the possibilities of assessing the gene network changes that occur during more rapid forms of cellular reprogramming, such as reprogramming by nuclear transfer and cell fusion [100]. Finally, it is exciting that human reprogramming methodologies and systems for integrative analysis are starting to catch up to the progress made in mice [15]. While human reprogramming is required for regenerative purposes, studying the interspecies differences between mice and human can illuminate the feasibility of using mouse reprogramming systems for both drug screening and disease modelling. While therapeutic cell transplantation remains an eventual goal of these reprogramming approaches, the integration of reprogrammed cells into disease modelling and drug screening protocols may have a more immediate impact on patient health. It is through this combination of rigorous bioinformatic analysis that the potential of reprogramming methodologies can be realized.

Acknowledgments Julein Sage and Marius Wernig are thanked for their critical review and exceptional mentorship. The helpful discussion with members of both the Sage and Wernig Laboratories was a great aid in the conceptual assembly of this paper. This work was supported by the Lucile Packard Foundation for Children's Health.

\section{Compliance with Ethical Standards}

Conflict of Interest The corresponding author states that there is no conflict of interest.
Human and Animal Rights and Informed Consent This article does not contain any studies with human or animal subjects performed by any of the authors.

\section{References}

1. Ambasudhan R, Talantova M, Coleman R, Yuan X, Zhu S, Lipton $\mathrm{SA}$, et al. Direct reprogramming of adult human fibroblasts to functional neurons under defined conditions. Cell Stem Cell. 2011;9(2):113-8. doi:10.1016/j.stem.2011.07.002.

2. Ang CE, Wernig M. Induced neuronal reprogramming. J Comp Neurol. 2014;522(12):2877-86. doi:10.1002/cne.23620.

3. Apostolou E, Hochedlinger K. Chromatin dynamics during cellular reprogramming. Nature. 2013;502(7472):462-71. doi:10. 1038/nature12749.

4. Batta K, Florkowska M, Kouskoff V, Lacaud G. Direct reprogramming of murine fibroblasts to hematopoietic progenitor cells. Cell Rep. 2014;9(5):1871-84. doi:10.1016/j.celrep.2014. 11.002 .

5. Benayoun BA, Pollina EA, Ucar D, Mahmoudi S, Karra K, Wong $\mathrm{ED}$, et al. H3K4me3 breadth is linked to cell identity and transcriptional consistency. Cell. 2014;158(3):673-88. doi:10.1016/j. cell.2014.06.027.

6. Bernstein BE, Mikkelsen TS, Xie X, Kamal M, Huebert DJ, Cuff $\mathrm{J}$, et al. A bivalent chromatin structure marks key developmental genes in embryonic stem cells. Cell. 2006;125(2):315-26. doi:10. 1016/j.cell.2006.02.041.

7. Bock C, Kiskinis E, Verstappen G, Gu H, Boulting G, Smith ZD, et al. Reference Maps of human ES and iPS cell variation enable high-throughput characterization of pluripotent cell lines. Cell. 2011;144(3):439-52. doi:10.1016/j.cell.2010.12.032.

8. Boyer LA, Lee TI, Cole MF, Johnstone SE, Levine SS, Zucker JP, et al. Core transcriptional regulatory circuitry in human embryonic stem cells. Cell. 2005;122(6):947-56. doi:10.1016/j.cell.2005.08. 020 .

9. Boyer LA, Plath K, Zeitlinger J, Brambrink T, Medeiros LA, Lee TI, et al. Polycomb complexes repress developmental regulators in murine embryonic stem cells. Nature. 2006;441(7091):349-53. doi:10.1038/nature04733.

10. Brambrink T, Foreman R, Welstead GG, Lengner CJ, Wernig M, Suh $\mathrm{H}$, et al. Sequential expression of pluripotency markers during direct reprogramming of mouse somatic cells. Cell Stem Cell. 2008;2(2):151-9. doi:10.1016/j.stem.2008.01.004.

11. Buganim Y, Faddah DA, Cheng AW, Itskovich E, Markoulaki S, Ganz K, et al. Single-cell expression analyses during cellular reprogramming reveal an early stochastic and a late hierarchic phase. Cell. 2012;150(6):1209-22. doi:10.1016/j.cell.2012.08.023.

12. Buganim Y, Faddah DA, Jaenisch R. Mechanisms and models of somatic cell reprogramming. Nat Rev Genet. 2013;14(6):427-39. doi:10.1038/nrg3473.

13. Buganim Y, Itskovich E, Hu YC, Cheng AW, Ganz K, Sarkar S, et al. Direct reprogramming of fibroblasts into embryonic Sertolilike cells by defined factors. Cell Stem Cell. 2012;11(3):373-86. doi:10.1016/j.stem.2012.07.019.

14. Buganim Y, Markoulaki S, van Wietmarschen N, Hoke H, Wu T, Ganz K, et al. The developmental potential of iPSCs is greatly influenced by reprogramming factor selection. Cell Stem Cell. 2014;15(3):295-309. doi:10.1016/j.stem.2014.07.003.

15. Cacchiarelli D, Trapnell C, Ziller MJ, Soumillon M, Cesana M, Karnik R, et al. Integrative analyses of human reprogramming 
reveal dynamic nature of induced pluripotency. Cell. 2015;162(2): 412-24. doi:10.1016/j.cell.2015.06.016.

16. Caiazzo M, Dell'Anno MT, Dvoretskova E, Lazarevic D, Taverna $\mathrm{S}$, Leo D, et al. Direct generation of functional dopaminergic neurons from mouse and human fibroblasts. Nature. 2011;476(7359): 224-7. doi:10.1038/nature10284.

17. Chanda S, Ang CE, Davila J, Pak C, Mall M, Lee QY, et al. Generation of induced neuronal cells by the single reprogramming factor ASCL1. Stem Cell Rep. 2014;3(2):282-96. doi:10.1016/j. stemcr.2014.05.020.

18. Chin MH, Mason MJ, Xie W, Volinia S, Singer M, Peterson C, et al. Induced pluripotent stem cells and embryonic stem cells are distinguished by gene expression signatures. Cell Stem Cell. 2009;5(1):111-23. doi:10.1016/j.stem.2009.06.008.

19. Chin MH, Pellegrini M, Plath K, Lowry WE. Molecular analyses of human induced pluripotent stem cells and embryonic stem cells. Cell Stem Cell. 2010;7(2):263-9. doi:10.1016/j.stem.2010.06. 019 .

20. Choi J, Lee S, Mallard W, Clement K, Tagliazucchi GM, Lim H, et al. A comparison of genetically matched cell lines reveals the equivalence of human iPSCs and ESCs. Nat Biotechnol. 2015;33(11):1173-81. doi:10.1038/nbt.3388.

21. Davis RL, Weintraub H, Lassar AB. Expression of a single transfected cDNA converts fibroblasts to myoblasts. Cell. 1987;51(6):987-1000.

22. De Los Angeles A, Ferrari F, Xi R, Fujiwara Y, Benvenisty N, Deng $\mathrm{H}$, et al. Hallmarks of pluripotency. Nature. 2015;525(7570):469-78. doi:10.1038/nature15515.

23. Denholtz M, Bonora G, Chronis C, Splinter E, de Laat W, Ernst J, et al. Long-range chromatin contacts in embryonic stem cells reveal a role for pluripotency factors and polycomb proteins in genome organization. Cell Stem Cell. 2013;13(5):602-16. doi:10. 1016/j.stem.2013.08.013.

24. Du Y, Wang J, Jia J, Song N, Xiang C, Xu J, et al. Human hepatocytes with drug metabolic function induced from fibroblasts by lineage reprogramming. Cell Stem Cell. 2014;14(3):394-403. doi: 10.1016/j.stem.2014.01.008

25. Durruthy-Durruthy J, Sebastiano V, Wossidlo M, Cepeda D, Cui J, Grow EJ, et al. The primate-specific noncoding RNA HPAT5 regulates pluripotency during human preimplantation development and nuclear reprogramming. Nat Genet. 2015. doi:10.1038/ ng.3449.

26. Efe JA, Hilcove S, Kim J, Zhou H, Ouyang K, Wang G, et al. Conversion of mouse fibroblasts into cardiomyocytes using a direct reprogramming strategy. Nat Cell Biol. 2011;13(3):215-22. doi:10.1038/ncb2164.

27. Encode Project Consortium. A user's guide to the encyclopedia of DNA elements (ENCODE). PLoS Biol. 2011;9(4):e1001046. doi: 10.1371/journal.pbio.1001046.

28. Fouse SD, Shen Y, Pellegrini M, Cole S, Meissner A, Van Neste L, et al. Promoter $\mathrm{CpG}$ methylation contributes to ES cell gene regulation in parallel with Oct4/Nanog, PcG complex, and histone $\mathrm{H} 3$ K4/K27 trimethylation. Cell Stem Cell. 2008;2(2):160-9. doi:10. 1016/j.stem.2007.12.011.

29. Fu JD, Stone NR, Liu L, Spencer CI, Qian L, Hayashi Y, et al. Direct reprogramming of human fibroblasts toward a cardiomyocyte-like state. Stem Cell Rep. 2013;1(3):235-47. doi: 10.1016/j.stemcr.2013.07.005.

30. Gore A, Li Z, Fung HL, Young JE, Agarwal S, AntosiewiczBourget J, et al. Somatic coding mutations in human induced pluripotent stem cells. Nature. 2011;471(7336):63-7. doi:10. 1038/nature09805.

31. Guenther MG, Frampton GM, Soldner F, Hockemeyer D, Mitalipova M, Jaenisch R, et al. Chromatin structure and gene expression programs of human embryonic and induced pluripotent stem cells. Cell Stem Cell. 2010;7(2):249-57. doi: 10.1016/j.stem.2010.06.015.

32. Hackett JA, Surani MA. Regulatory principles of pluripotency: from the ground state up. Cell Stem Cell. 2014;15(4):416-30. doi:10.1016/j.stem.2014.09.015.

33. Han JK, Chang SH, Cho HJ, Choi SB, Ahn HS, Lee J, et al. Direct conversion of adult skin fibroblasts to endothelial cells by defined factors. Circulation. 2014;130(14):1168-78. doi:10.1161/ CIRCULATIONAHA.113.007727.

34. Hanna J, Cheng AW, Saha K, Kim J, Lengner CJ, Soldner F, et al. Human embryonic stem cells with biological and epigenetic characteristics similar to those of mouse ESCs. Proc Natl Acad Sci U S A. 2010;107(20):9222-7. doi:10.1073/pnas.1004584107.

35. Hanna J, Markoulaki S, Schorderet P, Carey BW, Beard C, Wernig $\mathrm{M}$, et al. Direct reprogramming of terminally differentiated mature B lymphocytes to pluripotency. Cell. 2008;133(2):250-64. doi:10. 1016/j.cell.2008.03.028.

36. Hochedlinger K, Plath K. Epigenetic reprogramming and induced pluripotency. Development. 2009;136(4):509-23. doi:10.1242/ dev.020867.

37. Huang P, He Z, Ji S, Sun H, Xiang D, Liu C, et al. Induction of functional hepatocyte-like cells from mouse fibroblasts by defined factors. Nature. 2011;475(7356):386-9. doi:10.1038/ nature10116.

38. Huang P, Zhang L, Gao Y, He Z, Yao D, Wu Z, et al. Direct reprogramming of human fibroblasts to functional and expandable hepatocytes. Cell Stem Cell. 2014;14(3):370-84. doi:10.1016/j. stem.2014.01.003.

39. Hussein SM, Batada NN, Vuoristo S, Ching RW, Autio R, Narva E, et al. Copy number variation and selection during reprogramming to pluripotency. Nature. 2011;471(7336):58-62. doi:10.1038/nature09871.

40. Hussein SM, Puri MC, Tonge PD, Benevento M, Corso AJ, Clancy JL, et al. Genome-wide characterization of the routes to pluripotency. Nature. 2014;516(7530):198-206. doi:10.1038/ nature 14046

41. Ieda M, Fu JD, Delgado-Olguin P, Vedantham V, Hayashi Y, Bruneau BG, et al. Direct reprogramming of fibroblasts into functional cardiomyocytes by defined factors. Cell. 2010;142(3):37586. doi:10.1016/j.cell.2010.07.002.

42. Islam S, Kjallquist U, Moliner A, Zajac P, Fan JB, Lonnerberg P, et al. Characterization of the single-cell transcriptional landscape by highly multiplex RNA-seq. Genome Res. 2011;21(7):1160-7. doi:10.1101/gr.110882.110.

43. Iwafuchi-Doi M, Zaret KS. Pioneer transcription factors in cell reprogramming. Genes Dev. 2014;28(24):2679-92. doi:10.1101/ gad.253443.114.

44. Jopling C, Boue S, Izpisua Belmonte JC. Dedifferentiation, transdifferentiation and reprogramming: three routes to regeneration. Nat Rev Mol Cell Biol. 2011;12(2):79-89. doi: 10.1038/nrm3043.

45. Judson RL, Babiarz JE, Venere M, Blelloch R. Embryonic stem cell-specific microRNAs promote induced pluripotency. Nat Biotechnol. 2009;27(5):459-61. doi:10.1038/nbt.1535.

46. Kareta MS, Gorges LL, Hafeez S, Benayoun BA, Marro S, Zmoos $\mathrm{AF}$, et al. Inhibition of pluripotency networks by the $\mathrm{Rb}$ tumor suppressor restricts reprogramming and tumorigenesis. Cell Stem Cell. 2015;16(1):39-50. doi:10.1016/j.stem.2014.10.019.

47. Kim J, Chu J, Shen X, Wang J, Orkin SH. An extended transcriptional network for pluripotency of embryonic stem cells. Cell. 2008;132(6):1049-61. doi:10.1016/j.cell.2008.02.039.

48. Kim J, Woo AJ, Chu J, Snow JW, Fujiwara Y, Kim CG, et al. A Myc network accounts for similarities between embryonic stem and cancer cell transcription programs. Cell. 2010;143(2):313-24. doi:10.1016/j.cell.2010.09.010. 
49. Kim K, Doi A, Wen B, Ng K, Zhao R, Cahan P, et al. Epigenetic memory in induced pluripotent stem cells. Nature. 2010;467(7313):285-90. doi:10.1038/nature09342.

50. Koche RP, Smith ZD, Adli M, Gu H, Ku M, Gnirke A, et al. Reprogramming factor expression initiates widespread targeted chromatin remodeling. Cell Stem Cell. 2011;8(1):96-105. doi: 10.1016/j.stem.2010.12.001.

51. Lister R, Pelizzola M, Dowen RH, Hawkins RD, Hon G, TontiFilippini J, et al. Human DNA methylomes at base resolution show widespread epigenomic differences. Nature. 2009;462(7271):315-22. doi:10.1038/nature08514.

52. Loh YH, Wu Q, Chew JL, Vega VB, Zhang W, Chen X, et al. The Oct4 and Nanog transcription network regulates pluripotency in mouse embryonic stem cells. Nat Genet. 2006;38(4):431-40. doi: $10.1038 /$ ng 1760 .

53. Lujan E, Zunder ER, Ng YH, Goronzy IN, Nolan GP, Wernig M. Early reprogramming regulators identified by prospective isolation and mass cytometry. Nature. 2015;521(7552):352-6. doi:10. 1038/nature14274.

54. Luscombe NM, Greenbaum D, Gerstein M. What is bioinformatics? A proposed definition and overview of the field. Methods Inf Med. 2001;40(4):346-58.

55. Maherali N, Ahfeldt T, Rigamonti A, Utikal J, Cowan C, Hochedlinger K. A high-efficiency system for the generation and study of human induced pluripotent stem cells. Cell Stem Cell. 2008;3(3):340-5. doi:10.1016/j.stem.2008.08.003.

56. Maherali N, Sridharan R, Xie W, Utikal J, Eminli S, Arnold K, et al. Directly reprogrammed fibroblasts show global epigenetic remodeling and widespread tissue contribution. Cell Stem Cell. 2007;1(1):55-70. doi:10.1016/j.stem.2007.05.014.

57. Mahmoudi S, Brunet A. Aging and reprogramming: a two-way street. Curr Opin Cell Biol. 2012;24(6):744-56. doi:10.1016/j. ceb.2012.10.004.

58. Marro S, Pang ZP, Yang N, Tsai MC, Qu K, Chang HY, et al. Direct lineage conversion of terminally differentiated hepatocytes to functional neurons. Cell Stem Cell. 2011;9(4):374-82. doi:10. 1016/j.stem.2011.09.002.

59. Marson A, Levine SS, Cole MF, Frampton GM, Brambrink T, Johnstone S, et al. Connecting microRNA genes to the core transcriptional regulatory circuitry of embryonic stem cells. Cell. 2008;134(3):521-33. doi:10.1016/j.cell.2008.07.020.

60. Meissner A, Wernig M, Jaenisch R. Direct reprogramming of genetically unmodified fibroblasts into pluripotent stem cells. Nat Biotechnol. 2007;25(10):1177-81. doi:10.1038/nbt1335.

61. Mikkelsen TS, Hanna J, Zhang X, Ku M, Wernig M, Schorderet P, et al. Dissecting direct reprogramming through integrative genomic analysis. Nature. 2008;454(7200):49-55. doi:10.1038/ nature 07056.

62. Mikkelsen TS, Ku M, Jaffe DB, Issac B, Lieberman E, Giannoukos G, et al. Genome-wide maps of chromatin state in pluripotent and lineage-committed cells. Nature. 2007;448(7153): 553-60. doi:10.1038/nature06008.

63. Nam YJ, Song K, Luo X, Daniel E, Lambeth K, West K, et al. Reprogramming of human fibroblasts toward a cardiac fate. Proc Natl Acad Sci U S A. 2013;110(14):5588-93. doi:10.1073/pnas. 1301019110

64. Newman AM, Cooper JB. Lab-specific gene expression signatures in pluripotent stem cells. Cell Stem Cell. 2010;7(2):258 62. doi:10.1016/j.stem.2010.06.016.

65. Okita K, Ichisaka T, Yamanaka S. Generation of germlinecompetent induced pluripotent stem cells. Nature. 2007;448(7151):313-7. doi:10.1038/nature05934.

66. Onder TT, Kara N, Cherry A, Sinha AU, Zhu N, Bernt KM, et al. Chromatin-modifying enzymes as modulators of reprogramming. Nature. 2012;483(7391):598-602. doi:10.1038/nature10953.
67. Orkin SH, Wang J, Kim J, Chu J, Rao S, Theunissen TW, et al. The transcriptional network controlling pluripotency in ES cells. Cold Spring Harb Symp Quant Biol. 2008;73:195-202. doi:10. 1101/sqb.2008.72.001.

68. Pang ZP, Yang N, Vierbuchen T, Ostermeier A, Fuentes DR, Yang $T Q$, et al. Induction of human neuronal cells by defined transcription factors. Nature. 2011;476(7359):220-3. doi:10.1038/ nature 10202

69. Papp B, Plath K. Epigenetics of reprogramming to induced pluripotency. Cell. 2013;152(6):1324-43. doi:10.1016/j.cell. 2013.02.043.

70. Polo JM, Anderssen E, Walsh RM, Schwarz BA, Nefzger CM, Lim SM, et al. A molecular roadmap of reprogramming somatic cells into iPS cells. Cell. 2012;151(7):1617-32. doi:10.1016/j.cell. 2012.11.039.

71. Qian L, Huang Y, Spencer CI, Foley A, Vedantham V, Liu L, et al. In vivo reprogramming of murine cardiac fibroblasts into induced cardiomyocytes. Nature. 2012;485(7400):593-8. doi:10.1038/ nature11044.

72. Ramalho-Santos M, Yoon S, Matsuzaki Y, Mulligan RC, Melton DA. "Stemness": transcriptional profiling of embryonic and adult stem cells. Science. 2002;298(5593):597-600. doi:10.1126/ science. 1072530.

73. Riddell J, Gazit R, Garrison BS, Guo G, Saadatpour A, Mandal $\mathrm{PK}$, et al. Reprogramming committed murine blood cells to induced hematopoietic stem cells with defined factors. Cell. 2014;157(3):549-64. doi:10.1016/j.cell.2014.04.006.

74. Samavarchi-Tehrani P, Golipour A, David L, Sung HK, Beyer TA, Datti A, et al. Functional genomics reveals a BMP-driven mesenchymal-to-epithelial transition in the initiation of somatic cell reprogramming. Cell Stem Cell. 2010;7(1):64-77. doi:10. 1016/j.stem.2010.04.015.

75. Schmidt R, Plath K. The roles of the reprogramming factors Oct4, Sox 2 and Klf4 in resetting the somatic cell epigenome during induced pluripotent stem cell generation. Genome Biol. 2012;13(10):251. doi:10.1186/gb-2012-13-10-251.

76. Sekiya S, Suzuki A. Direct conversion of mouse fibroblasts to hepatocyte-like cells by defined factors. Nature. 2011;475(7356): 390-3. doi:10.1038/nature10263.

77. Smith A. A glossary for stem-cell biology. Nature. 2006;441: 1060. doi:10.1038/nature04954.

78. Song K, Nam YJ, Luo X, Qi X, Tan W, Huang GN, et al. Heart repair by reprogramming non-myocytes with cardiac transcription factors. Nature. 2012;485(7400):599-604. doi:10.1038/ nature 11139

79. Soufi A, Donahue G, Zaret KS. Facilitators and impediments of the pluripotency reprogramming factors' initial engagement with the genome. Cell. 2012;151(5):994-1004. doi:10.1016/j.cell. 2012.09.045.

80. Sperger JM, Chen X, Draper JS, Antosiewicz JE, Chon CH, Jones $\mathrm{SB}$, et al. Gene expression patterns in human embryonic stem cells and human pluripotent germ cell tumors. Proc Natl Acad Sci U S A. 2003;100(23):13350-5. doi:10.1073/pnas.2235735100.

81. Sridharan R, Tchieu J, Mason MJ, Yachechko R, Kuoy E, Horvath $\mathrm{S}$, et al. Role of the murine reprogramming factors in the induction of pluripotency. Cell. 2009;136(2):364-77. doi:10.1016/j.cell. 2009.01.001.

82. Srivastava D, Yu P. Recent advances in direct cardiac reprogramming. Curr Opin Genet Dev. 2015;34:77-81. doi:10. 1016/j.gde.2015.09.004.

83. Stadtfeld M, Hochedlinger K. Induced pluripotency: history, mechanisms, and applications. Genes Dev. 2010;24(20):223963. doi:10.1101/gad.1963910.

84. Stadtfeld M, Maherali N, Breault DT, Hochedlinger K. Defining molecular cornerstones during fibroblast to iPS cell 
reprogramming in mouse. Cell Stem Cell. 2008;2(3):230-40. doi: 10.1016/j.stem.2008.02.001.

85. Szabo E, Rampalli S, Risueno RM, Schnerch A, Mitchell R, Fiebig-Comyn A, et al. Direct conversion of human fibroblasts to multilineage blood progenitors. Nature. 2010;468(7323):5216. doi:10.1038/nature09591.

86. Tabar V, Studer L. Pluripotent stem cells in regenerative medicine: challenges and recent progress. Nat Rev Genet. 2014;15(2):8292. doi: $10.1038 / \operatorname{nrg} 3563$.

87. Takahashi K, Tanabe K, Ohnuki M, Narita M, Ichisaka T, Tomoda $\mathrm{K}$, et al. Induction of pluripotent stem cells from adult human fibroblasts by defined factors. Cell. 2007;131(5):861-72. doi:10. 1016/j.cell.2007.11.019.

88. Takahashi K, Yamanaka S. Induction of pluripotent stem cells from mouse embryonic and adult fibroblast cultures by defined factors. Cell. 2006;126(4):663-76. doi:10.1016/j.cell.2006.07. 024.

89. Tanabe K, Haag D, Wernig M. Direct somatic lineage conversion. Philos Trans R Soc Lond Ser B Biol Sci. 2015;370(1680), 20140368. doi:10.1098/rstb.2014.0368.

90. Tonge PD, Corso AJ, Monetti C, Hussein SM, Puri MC, Michael IP, et al. Divergent reprogramming routes lead to alternative stemcell states. Nature. 2014;516(7530):192-7. doi:10.1038/ nature14047.

91. Utikal J, Polo JM, Stadtfeld M, Maherali N, Kulalert W, Walsh RM, et al. Immortalization eliminates a roadblock during cellular reprogramming into iPS cells. Nature. 2009;460(7259):1145-8. doi:10.1038/nature08285.

92. Vierbuchen T, Ostermeier A, Pang ZP, Kokubu Y, Sudhof TC, Wernig M. Direct conversion of fibroblasts to functional neurons by defined factors. Nature. 2010;463(7284):1035-41. doi:10. 1038/nature08797.

93. Wada $\mathrm{R}$, Muraoka $\mathrm{N}$, Inagawa $\mathrm{K}$, Yamakawa $\mathrm{H}$, Miyamoto $\mathrm{K}$, Sadahiro T, et al. Induction of human cardiomyocyte-like cells from fibroblasts by defined factors. Proc Natl Acad Sci U S A. 2013;110(31):12667-72. doi:10.1073/pnas.1304053110.

94. Wang J, Rao S, Chu J, Shen X, Levasseur DN, Theunissen TW, et al. A protein interaction network for pluripotency of embryonic stem cells. Nature. 2006;444(7117):364-8. doi:10.1038/ nature05284.

95. Wapinski OL, Vierbuchen T, Qu K, Lee QY, Chanda S, Fuentes $\mathrm{DR}$, et al. Hierarchical mechanisms for direct reprogramming of fibroblasts to neurons. Cell. 2013;155(3):621-35. doi:10.1016/j. cell.2013.09.028.

96. Wernig M, Lengner CJ, Hanna J, Lodato MA, Steine E, Foreman $\mathrm{R}$, et al. A drug-inducible transgenic system for direct reprogramming of multiple somatic cell types. Nat Biotechnol. 2008;26(8):916-24. doi:10.1038/nbt1483.

97. Wernig M, Meissner A, Foreman R, Brambrink T, Ku M, Hochedlinger $\mathrm{K}$, et al. In vitro reprogramming of fibroblasts into a pluripotent ES-cell-like state. Nature. 2007;448(7151):318-24. doi:10.1038/nature05944.

98. Xie H, Ye M, Feng R, Graf T. Stepwise reprogramming of B cells into macrophages. Cell. 2004;117(5):663-76.

99. Xu J, Du Y, Deng H. Direct lineage reprogramming: strategies, mechanisms, and applications. Cell Stem Cell. 2015;16(2):119 34. doi:10.1016/j.stem.2015.01.013.

100. Yamanaka S, Blau HM. Nuclear reprogramming to a pluripotent state by three approaches. Nature. 2010;465(7299):704-12. doi: 10.1038/nature09229.

101. Yang R, Zheng Y, Li L, Liu S, Burrows M, Wei Z, et al. Direct conversion of mouse and human fibroblasts to functional melanocytes by defined factors. Nat Commun. 2014;5:5807. doi:10.1038/ ncomms6807.

102. Yoo AS, Sun AX, Li L, Shcheglovitov A, Portmann T, Li Y, et al. MicroRNA-mediated conversion of human fibroblasts to neurons. Nature. 2011;476(7359):228-31. doi:10.1038/nature10323.

103. Young RA. Control of the embryonic stem cell state. Cell. 2011;144(6):940-54. doi:10.1016/j.cell.2011.01.032.

104. Yu B, He ZY, You P, Han QW, Xiang D, Chen F, et al. Reprogramming fibroblasts into bipotential hepatic stem cells by defined factors. Cell Stem Cell. 2013;13(3):328-40. doi:10. 1016/j.stem.2013.06.017.

105. Yu J, Vodyanik MA, Smuga-Otto K, Antosiewicz-Bourget J, Frane JL, Tian S, et al. Induced pluripotent stem cell lines derived from human somatic cells. Science. 2007;318(5858):1917-20. doi:10.1126/science.1151526.

106. Zaret KS, Carroll JS. Pioneer transcription factors: establishing competence for gene expression. Genes Dev. 2011;25(21):222741. doi:10.1101/gad.176826.111.

107. Zunder ER, Lujan E, Goltsev Y, Wernig M, Nolan GP. A continuous molecular roadmap to iPSC reprogramming through progression analysis of single-cell mass cytometry. Cell Stem Cell. 2015;16(3):323-37. doi:10.1016/j.stem.2015.01.015. 